\title{
Influence of calcination temperature on structural and magnetic properties of nanocomposites formed by Co-ferrite dispersed in sol-gel silica matrix using tetrakis(2-hydroxyethyl) orthosilicate as precursor
}

\author{
Mehrnaz Gharagozlou
}

\begin{abstract}
Effects of calcination temperatures varying from 400 to $1000^{\circ} \mathrm{C}$ on structural and magnetic properties of nanocomposites formed by Co-ferrite dispersed in the sol-gel silica matrix using tetrakis(2-hydroxyethyl) orthosilicate (THEOS) as water-soluble silica precursor have been investigated. Studies carried out using XRD, FT-IR, TEM, STA (TG-DTG-DTA) and VSM techniques. Results indicated that magnetic properties of samples such as superparamagnetism and ferromagnetism showed great dependence on the variation of the crystallinity and particle size caused by the calcination temperature. The crystallization, saturation magnetization $M_{s}$ and remenant magnetization $M_{r}$ increased as the calcination temperature increased. But the variation of coercivity $\mathrm{H}_{c}$ was not in accordance with that of $M_{s}$ and $M_{r}$ indicating that $H_{c}$ is not determined only by the crystallinity and size of $\mathrm{CoFe}_{2} \mathrm{O}_{4}$ nanoparticles. TEM images showed spherical nanoparticles dispersed in the silica network with sizes of 10$30 \mathrm{~nm}$. Results showed that the well-established silica network provided nucleation locations for $\mathrm{CoFe}_{2} \mathrm{O}_{4}$ nanoparticles to confinement the coarsening and aggregation of nanoparticles. THEOS as silica matrix network provides an ideal nucleation environment to disperse $\mathrm{CoFe}_{2} \mathrm{O}_{4}$ nanoparticles and thus to confine them to aggregate and coarsen. By using THEOS as water-soluble silica precursor over the currently used TEOS and TMOS, the organic solvents are not needed owing to the complete solubility of THEOS in water. Synthesized nanocomposites with adjustable particle sizes and controllable magnetic properties make the applicability of Coferrite even more versatile.
\end{abstract}

\section{Background}

Magnetic nanocomposites consisting of spinel ferrite nanoparticles in a non magnetic $\mathrm{SiO}_{2}$ matrix exhibit interesting properties arising in size effects and magnetic interactions [1-5]. Among them, $\mathrm{CoFe}_{2} \mathrm{O}_{4}-\mathrm{SiO}_{2}$ magnetic nanocomposites have high potential for applications as magnetic fluids [6], drug delivery [7], and high density information storage [8] due to remarkable properties of bulk cobalt ferrite (high saturation magnetization and coercivity, strong anisotropy, mechanical hardness and chemical stability) [9], combined with the

Correspondence: gharagozlou@icrc.ac.ir

Department of Nanotechnology and Nanomaterials, Institute for Color Science and Technology, P.O. Box 16765-654 Tehran, Iran magnetic properties characteristic of nanoparticles, which depend strongly on particle shape and size, particle-matrix interactions and degree of dispersion throughout the matrix. Recently, cobalt ferrite nanoparticles were also known to be a photomagnetic material that shows a remarkable light induced coercivity change [10-12].

Based on the above technological challenge and scientific importance, researches such as ceramic method [13], sol-gel [14], co-precipitation [15], solvent evaporation [16], hydrothermal [17], combustion [18], microemulsion [19] and citrate methods [20] have been made into various synthesis routes of nanocrystalline ferrites. In the earlier report, cobalt ferrite nanoparticles have 
been synthesized by the polymeric precursor method [21]. While the nanoparticles obtained usually have a strong tendency to aggregate, this makes it very difficult to exploit their unique physical properties [22]. To reduce the unwanted crystallite coarsening and particles aggregation, attempts have been made to synthesize nanocomposites by embedding ferrite nanoparticles in a suitable matrix [23]. Different matrixes such as resins [24], polymer films [25] and silica glasses [26,27] have been studied. Studies on magnetic nanocomposites of ferrite nanoparticles dispersed in the silica matrix $[28,29]$ have revealed a behavior different from that of bulk systems.

Among various synthetic routes, sol-gel process has proved to be an efficient method to prepare ultra-fine particles dispersed in different matrices. Through this method, a good control of the sample morphology, texture, structure, and chemical composition can be attained by carefully monitoring the preparation parameters. The size and morphology of the nanoparticles and their properties may be controlled by modifying the composition of the nanocomposites and by thermal treatment conditions [30]. This is the reason why the sol-gel synthesis method has gone an intensive development.

Tetraalkoxysilanes (tetramethoxysilane, TMOS and tetraethoxysilane, TEOS) are common precursors to synthesize silicate. Their hydrolysis in aqueous solutions and further polycondensation reactions cause formation of sol particles of which the cross-linking leads to the self-organization into a porous three-dimensional network in the bulk. In view of the fact that tetraalkoxysilanes are poor-water soluble compounds, methanol or ethanol is generally added to avoid the phase separation $[31,32]$. This problem has been countered by the use of polyol silicates possessing improved water solubility [33] I. Gill and A. Ballesteros, Encapsulation of biologicals within silicate, siloxane, and hybrid sol-gel polymers: an efficient and generic approach. J. Am. Chem. Soc. (1998), pp. 8587-8598. TMOS and TEOS, as shown recently in [34], can be also exchanged for tetrakis(2hydroxyethyl) orthosilicate (THEOS). This completely water-soluble precursor forms nanocomposite monolithic material in aqueous solutions in the absence of added alcohol.

In this paper, effects of calcination temperature on structural and magnetic properties of cobalt ferrite nanocomposites in silica matrix prepared by sol-gel method using tetrakis(2-hydroxyethyl) orthosilicate (THEOS) as silica precursor have been reported aiming at tuning the magnetic properties of $\mathrm{CoFe}_{2} \mathrm{O}_{4}$ nanoparticles dispersed in a sol gel silica matrix and greatly expanding the range of applications by adjusting the calcination temperature. Also, FT-IR and thermal analysis (TG-DTG-DTA) of the alcogel precursor have been carried out. Therefore, special attention is given to the correlation between the structural and magnetic properties of $\mathrm{CoFe}_{2} \mathrm{O}_{4}$ nanoparticles embedded in THEOS as silica precursor for different calcination temperatures.

\section{Experimental}

All the chemicals were of analytical grade and used without any further purification. Nanocomposites of cobalt ferrite dispersed in a silica matrix were prepared by sol-gel process using tetrakis(2-hydroxyethyl) orthosilicate (THEOS) as a water-soluble silica precursor of silica and metallic nitrates as precursors of the ferrite. The THEOS: $\mathrm{H}_{2} \mathrm{O}$ and Fe:Co molar ratios were controlled at $1: 5$ and $2: 1$, respectively. The weight ratio of nanocomposites was $30 \mathrm{wt} . \% \mathrm{CoFe}_{2} \mathrm{O}_{4}$ in the silica matrix. The sol was prepared by dissolving $\mathrm{Fe}$ $\left(\mathrm{NO}_{3}\right)_{3} \cdot 9 \mathrm{H}_{2} \mathrm{O}$ and $\mathrm{Co}\left(\mathrm{NO}_{3}\right)_{2} \cdot 6 \mathrm{H}_{2} \mathrm{O}$ in deionized water, followed by the addition of the aqueous solution of THEOS. After vigorous stirring for $1 \mathrm{~h}$, the sol was allowed to gel at room temperature for some days in a partially closed glass vessel. The obtained alcogel was put into an oven for further drying at $110^{\circ} \mathrm{C}$ for $24 \mathrm{~h}$ to obtain the xerogel. The xerogel was calcined at different temperatures varying from 400 to $1000^{\circ} \mathrm{C}$ for $2 \mathrm{~h}$ with a heating rate of $10^{\circ} \mathrm{C} / \mathrm{min}$ in ambient atmosphere.

X-ray diffraction (XRD) patterns were collected using a Philips PNA-analytical diffractometer with $\mathrm{CuK \alpha}$ radiation. FT-IR spectra $\left(500-4000 \mathrm{~cm}^{-1}\right)$ were recorded on a Perkin Elmer Spectrum One spectrophotometer with $\mathrm{KBr}$ pellets. Thermal analyses (TG-DTG-DTA) including the thermogravimetery (TG), derivative thermogravimetery (DTG) and differential thermal analysis (DTA) were carried out using a Perkin Elmer simultaneous thermal analyzer (STA Pyris Diamond Model) with the heating rate of $5^{\circ} \mathrm{C} / \mathrm{min}$ in flowing air. The TEM images and selected area electron diffraction (SAED) pattern were recorded on a Philips CM 200 FEG transmission electron microscope. Magnetic measurements were carried out at room temperature using a vibrating sample magnetometer (VSM).

\section{Results and Discussion}

\section{$\mathrm{X}$-ray diffraction (XRD) analysis}

The XRD patterns of the samples calcined at different temperatures varying from 400 to $1000^{\circ} \mathrm{C}$ were shown in Figure 1 to investigate the influence of the calcination temperature on the structure. The weak diffraction peaks assigned to $\mathrm{CoFe}_{2} \mathrm{O}_{4}$ appeared at $400^{\circ} \mathrm{C}$ suggesting that the particles of $\mathrm{CoFe}_{2} \mathrm{O}_{4}$ had been nucleated in the silica matrix. X-ray diffraction patterns showed poor crystallinity up to calcination temperature of $600^{\circ} \mathrm{C}$.

Our results showed that with increasing calcination temperature, the intensity of peaks increases and the 


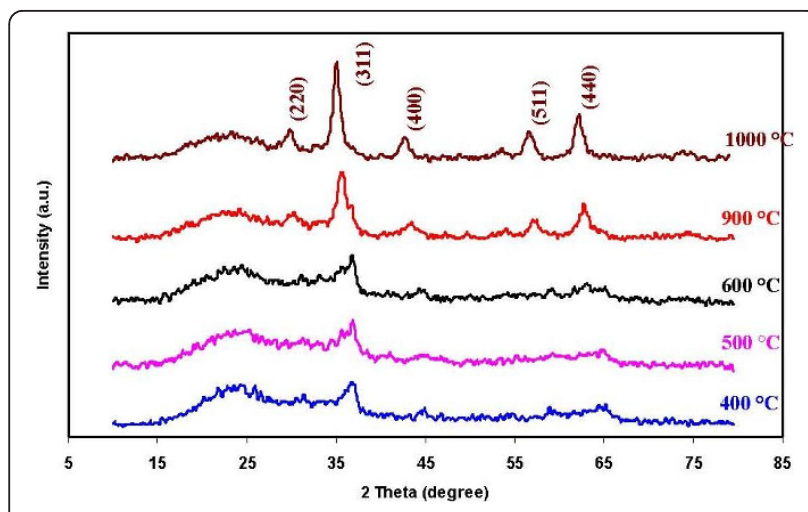

Figure 1 XRD patterns of the nanocomposite samples calcined at different temperatures varying from 400 to $1000^{\circ} \mathrm{C}$.

diffraction peaks become sharper and narrower. This indicates the enhancement of the crystallinity which originated from the increment of the crystalline volume ratio due to the size enlargement of the nuclei $[35,36]$. The full-width at half maximum (FWHM) of the diffraction peaks decreases with increasing calcination temperature discloses that the average crystallite size is becoming bigger correspondingly. The very broad peak at $2 \theta$ of around $23^{\circ}$ in XRD patterns of all samples was attributed to the characteristic diffraction peak of the amorphous $\mathrm{SiO}_{2}$ matrix.

All of the diffraction peaks confirmed the formation of the pure single-phase cobalt ferrite with the face-centered cubic spinel phase and Fd3 m ( 2227$)$ space group. No diffraction peaks of impurities were observed in the patterns. It showed that in comparison with the previous report using TEOS as a silica precursor [37], Co-ferrites with more crystallinity have been successfully synthesized at lower calcination temperatures under current mild experimental conditions.

The increase of the calcination temperature results in sharper peaks with the increased intensity and higher crystallization without changes in the obtained phases.

The influence of the calcination temperature on the crystallite sizes of the nanocomposite samples were shown in Tables 1.

Table 1 Crystallite size and magnetic properties of the nanocomposite samples calcined at different temperatures varying from 400 to $1000^{\circ} \mathrm{C}$

\begin{tabular}{lcccc}
\hline $\begin{array}{l}\text { Temperature } \\
\left({ }^{\circ} \mathbf{C}\right)\end{array}$ & $\begin{array}{c}\text { Crystallite size } \\
(\mathbf{n m})\end{array}$ & $\begin{array}{c}\mathbf{M}_{\mathbf{s}} \\
(\mathbf{e m} \mathbf{m} / \mathbf{g})\end{array}$ & $\begin{array}{c}\mathbf{M}_{\mathbf{r}} \\
(\mathbf{e m u} / \mathbf{g})\end{array}$ & $\begin{array}{c}\text { Coercivity Hc } \\
(\mathbf{O e})\end{array}$ \\
\hline 400 & 5.9 & 0.21 & 0.004 & 27 \\
500 & 8.6 & 0.77 & 0.006 & 43 \\
600 & 9.3 & 1.67 & 0.009 & 19 \\
900 & 29.6 & 9.56 & 0.804 & 82 \\
1000 & 34.3 & 12.01 & 2.130 & 220 \\
\hline
\end{tabular}

The crystallite size of all samples prepared at different calcination temperatures estimated from XRD peak broadening using Scherrer's formula [38]

$$
t=\frac{0.9 \lambda}{\beta \cos \theta}
$$

where $t$ is the crystallite size, $\lambda$ the wavelength of $X$ ray radiation $(\mathrm{CuK} \alpha), \theta$ the Bragg angle and $\beta$ is the full width at half maximum (FWHM) of the most intense diffraction peak (311). The crystallinity and crystallite size increase at higher calcination temperatures, indicating that the silica network plays an important role in restricting the growth and aggregation of Co-ferrite nanoparticles.

\section{FT-IR analysis}

Figure 2 shows the FT-IR spectra of the alcogel precursor and $\mathrm{CoFe}_{2} \mathrm{O}_{4} / \mathrm{SiO}_{2}$ samples calcined at different temperatures varying from 400 to $1000^{\circ} \mathrm{C}$. The broad band at $1630 \mathrm{~cm}^{-1}$ in the IR spectrum of the alcogel ascribed to the $\mathrm{H}-\mathrm{O}-\mathrm{H}$ bending vibration of the free or absorbed water. As shown in Figure 2(a), the band at $1384 \mathrm{~cm}^{-1}$ is associated with the antisymmetric $\mathrm{NO}_{3}{ }^{-}$ stretching vibration arising from the residual nitrate groups in the alcogel. Using THEOS as precursor, the silica network is formed and characterized by the strong absorptions at 1076,825 and $471 \mathrm{~cm}^{-1}$ corresponding to the $\mathrm{Si}-\mathrm{O}-\mathrm{Si}$ antisymmetric stretching and bending mode [39] which shows a shift to lower wavelength in comparison with the previous report using TEOS as silica precursor [40].

In IR spectra of samples calcined at different temperatures varying from 400 to $1000^{\circ} \mathrm{C}$, the intensities of the broad bands associated with the absorbed water are drastically weakened. Also, the disappearance of the absorption at $1384 \mathrm{~cm}^{-1}$ could be ascribed to the complete decomposition of the nitrate species after

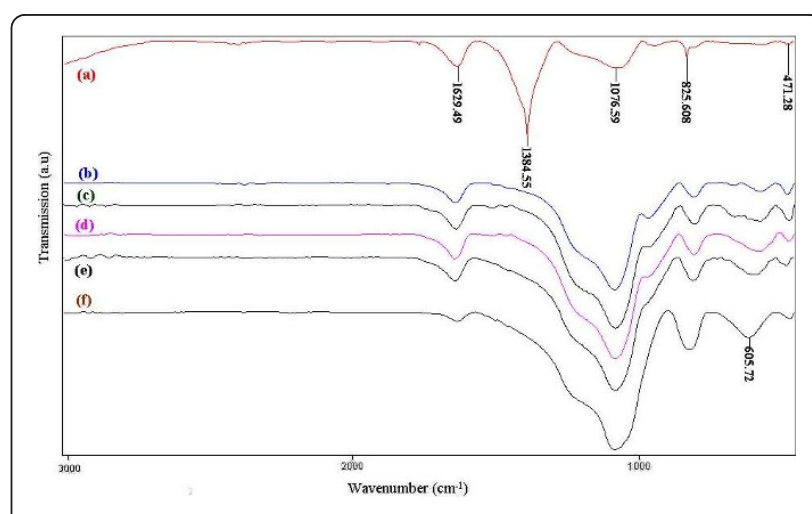

Figure 2 FT-IR spectra of (a) alcogel and nanocomposite samples calcined at (b) $400^{\circ} \mathrm{C}$, (c) $500^{\circ} \mathrm{C}$, (d) $600^{\circ} \mathrm{C}$, (e) $900^{\circ} \mathrm{C}$, (f) $1000^{\circ} \mathrm{C}$. 
calcination, as confirmed by the thermal analysis. The band at $605 \mathrm{~cm}^{-1}$ assigned to the $\mathrm{Si}-\mathrm{O}-\mathrm{Fe}$ vibration increases in intensity with increasing the calcination temperature, which can be ascribed to the enhanced interactions between $\mathrm{CoFe}_{2} \mathrm{O}_{4}$ particles and the silica matrix [41]. The characteristic absorptions for the silica network slightly increased in intensity with increasing calcination temperature. With increasing the calcination temperature the intensity of $\equiv \mathrm{Si}-\mathrm{O}-\mathrm{Si} \equiv$ absorption band of the $\mathrm{SiO}_{4}$ tetrahedron of the silica network at 1079 $\mathrm{cm}^{-1}$ increases.

\section{Thermal analysis}

The simultaneous thermal analyses (TG-DTG-DTA) of the alcogel were shown in Figure 3. The thermogravimetery (TG) and derivative thermogravimetery (DTG) curves show two stages of the weight loss. First stage of the weight loss at about $100^{\circ} \mathrm{C}$ was attributed to the loss of water and some gases adsorbed on the surface, which corresponds to an endothermic peak in the differential
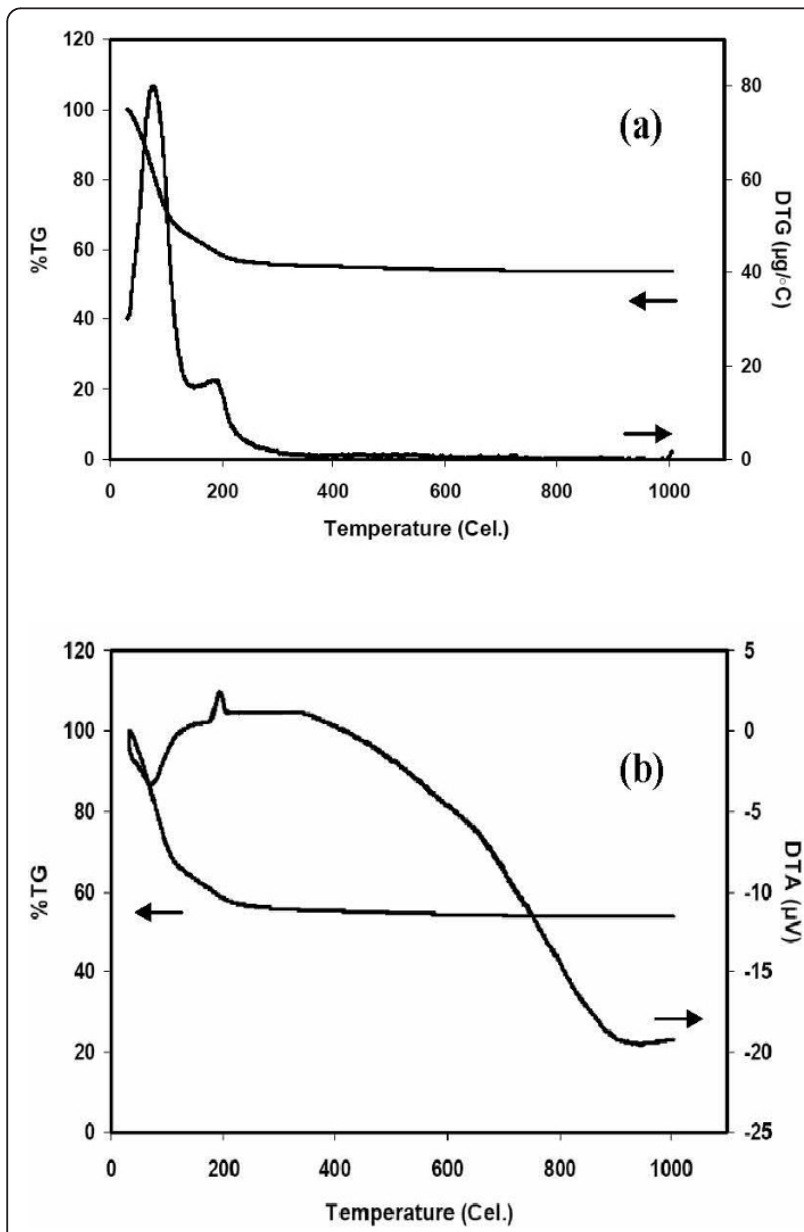

Figure 3 Thermal analyses of the alcogel (a) TG-DTA and (b) TG-DTG. thermal analysis (DTA) curve. The second one at about $200^{\circ} \mathrm{C}$ was ascribed to the burning of residual organic groups accompanied by an exothermic peak in the DTA curve which occurs at lower temperature in contrast to the previous report using TEOS as a silica precursor [42]. We can observe a broad endothermic event between $800-1000^{\circ} \mathrm{C}$ associated with the densification of the nanocomposites. Above $300^{\circ} \mathrm{C}$ the weight loss is almost negligible showing that the majority of the mass loss occurs under $300^{\circ} \mathrm{C}$ which allows for optimization of the calcination temperature. These results were in agreement with the FT-IR spectroscopy and XRD ones.

\section{Transmission electron microscopy (TEM) analysis}

TEM images and selected area electron diffraction (SAED) pattern of the nanocomposites calcined at 600 and $800^{\circ} \mathrm{C}$ were shown in Figure 4. TEM observations indicate that almost spherical Co-ferrite nanoparticles were embedded in the silica network. The average particle sizes of the nanocomposites calcined at 600 and $800^{\circ}$ $C$ were about $10 \mathrm{~nm}$ and $27 \mathrm{~nm}$, respectively, in accordance with the results obtained from XRD analyses according to the Scherrer's formula. The diffraction dots and diffuse rings of different lattice planes in the SAED pattern (Figure 4c) were in good agreement with the present spinel system.

\section{Magnetic measurements}

To investigate the influence of the calcination temperature on magnetic properties of nanocomposite samples, hysteresis loops of samples calcined at different temperatures varying from 400 to $1000^{\circ} \mathrm{C}$ were analyzed by VSM, as shown in Figure 5. Also, the corresponding magnetic parameters were listed in Tables 1.

It can be observed that the values of $M_{s}$ and $M_{r}$ were increased by increasing the temperature from 400 to $1000^{\circ} \mathrm{C}$ which arising from spin non-colinearity at the surface of the crystals. The changes in the magnetic properties of the samples can be attributed to the modification of the crystallinity and crystallite sizes dependent on the calcination temperature. The energy of a magnetic particle in the external field is proportional to its particle sizes via the number of molecules in a single magnetic domain. Therefore, the decrease of the $M_{s}$ values with the decrease of particle sizes can be attributed to surface effects that are the result of finite-size scaling of nanocrystallites [43].

The variation of the saturation magnetization $M_{s}$ and remanent magnetization $M_{r}$ as a function of temperature were shown in Figure 6. To calculate the saturation magnetization $\left(M_{s}\right)$ the magnetization values $(M)$ were plotted vs. $1 / \mathrm{H}$. The $\mathrm{M}_{\mathrm{s}}$ was calculated from the extrapolation of the magnetic curve at the magnitude of $\mathrm{M}$ when $1 / \mathrm{H} \approx 0$ (Tables 1 ). 


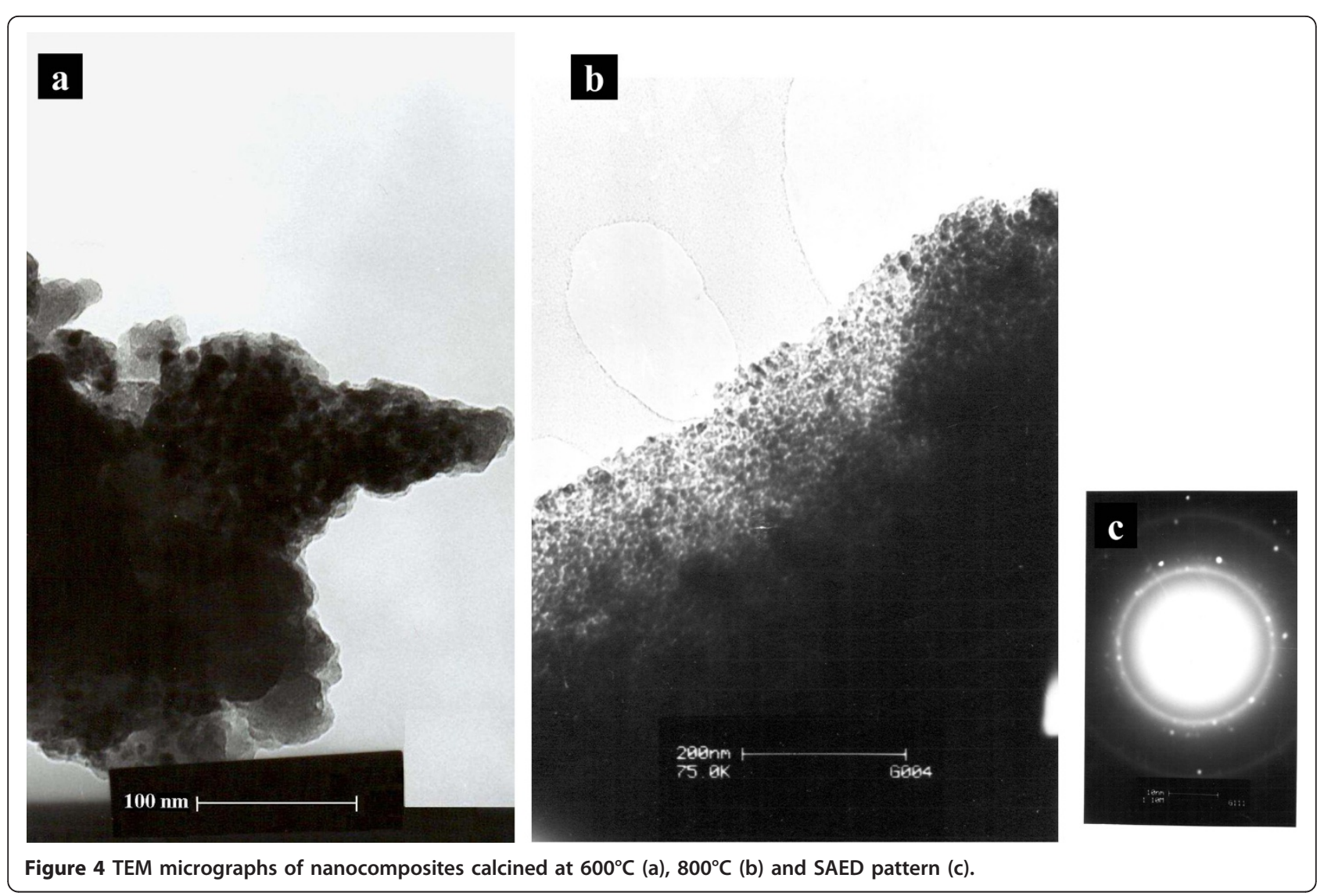

It can be observed that the $M_{s}$ and $M_{r}$ values for samples calcined at different temperatures were increased by increasing the temperature (Figure 5). This type of behavior is entirely consistent with a model of particle growth in the system in such a way that differences in the magnetic parameters are associated with changes in the particle size [43]. The variation of coercivity $\mathrm{H}_{c}$ was not in accordance with that of $M_{s}$ and $M_{r}$, indicating

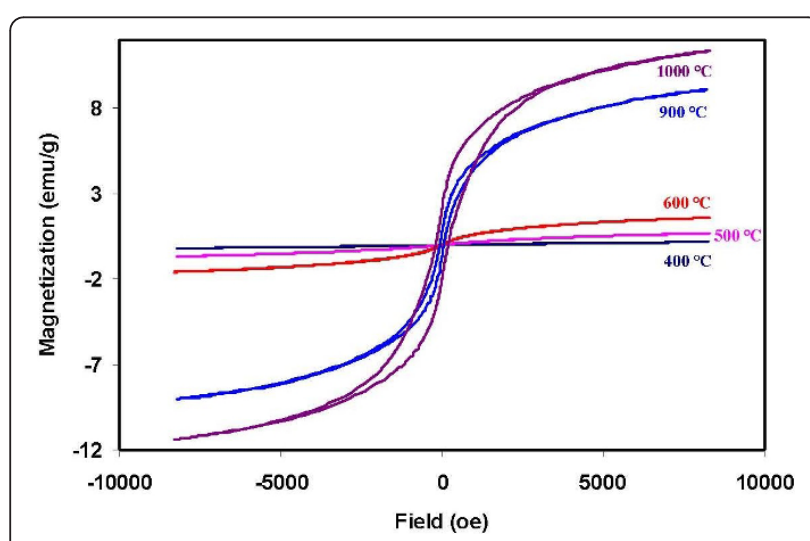

Figure 5 Hysteresis loops of nanocomposite samples calcined at different temperatures varying from 400 to $1000^{\circ} \mathrm{C}$. that $\mathrm{H}_{\mathrm{c}}$ is not determined only by the size of nanoparticles. $\mathrm{H}_{\mathrm{c}}$ values were significantly less than previous reports using TEOS as a silica precursor $[37,40]$. Therefore changes in magnetic properties such as superparamagnetism and ferromagnetism of samples can be recognized by the modification of the crystallinity and crystallite sizes dependent on the calcination temperature [44]. The lower $M_{s}$ values related to the particles with the smaller size could be attributed to the surface distortion due to the interaction of transition metal ions in the spinel lattice with the oxygen atoms, which can reduce [45] the net magnetic moment in the particle. This effect is particularly prominent for the ultrafine particles due to their large surface to volume ratio. Finite size effects have been reported as being responsible for the reduction of the saturation magnetization of nanoparticles [46].

It is found that the $\mathrm{M}-\mathrm{H}$ curves of samples calcined at $400-600^{\circ} \mathrm{C}$ take on incomplete reversibility, and corresponding $\mathrm{M}_{\mathrm{r}}$ values is about $0.01 \mathrm{emu} / \mathrm{g}$, which means that samples are superparamagnetic. When the calcination temperature is up to or above $800^{\circ} \mathrm{C}$, typical saturated hysteresis loops can be observed. For samples calcined at $400-600^{\circ} \mathrm{C}$, the size of most nanoparticles is smaller than the critical size to remain ferromagnetic; 


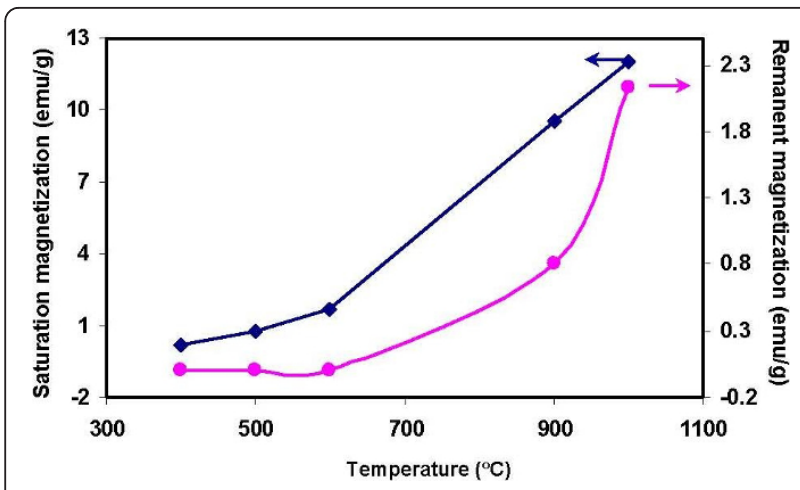

Figure 6 Variation of $M_{s}$ and $M_{r}$ of nanocomposite samples as a function of the calcination temperature.

hence they will show superparamagnetic behavior. However, if the calcination temperature is increased until the size of most nanocrystallites exceeds the critical size, there will be noncoherent magnetization change in the nanoparticles themselves, and sample shows ferromagnetic properties. Therefore, we can change the calcination temperature of nanocomposites to achieve ideal magnetic properties and behavior. Calcination temperatures at $400-600^{\circ} \mathrm{C}$ can be applied if samples used in areas such as ferrofluid technology which $\mathrm{CoFe}_{2} \mathrm{O}_{4}$ should be of superparamagnetic.

\section{Conclusions}

In summary, the influence of the calcination temperature on the magnetic properties and crystallinity of cobalt ferrite nanocomposites successfully synthesized by sol-gel method using tetrakis(2-hydroxyethyl) orthosilicate (THEOS) have been investigated with the aim of tuning the magnetic properties and greatly expanding the range of applications. The tetrakis(2-hydroxyethyl) orthosilicate as silica matrix network provides an ideal nucleation environment to disperse $\mathrm{CoFe}_{2} \mathrm{O}_{4}$ nanoparticles and thus to confine them to aggregate and coarsen. By using THEOS as precursor over the currently used TEOS and TMOS, the organic solvents are not needed owing to the complete solubility of THEOS in water. Particle sizes of the samples increased with the calcination temperature. Our results showed that the magnetic properties of the nanocomposite samples were strongly affected by the calcination temperature as a consequence of the gradual increase in the crystallinity and particle size. The saturation magnetization for all the samples was lower than that of the $\mathrm{CoFe}_{2} \mathrm{O}_{4}$ bulk phase owing to the particle sizes obtained. Therefore, sizeadjustable and magnetic controllable cobalt ferrite nanoparticles were obtained by embedding $\mathrm{CoFe}_{2} \mathrm{O}_{4}$ particles in the amorphous silica network and controlling suitable calcination temperature. The magnetic properties of the synthesized nanocomposites indicate that these materials have good potential for important technological applications, e.g. in ferrofluid technology, bioprocessing and magneto-optical devices.

\section{Acknowledgements}

It would be acknowledged that this work was supported by the National Elite Foundation. We are also grateful to the Institute for Color Science and Technology for their support.

\section{Authors' contributions}

MG performed experiments, data analysis and wrote the manuscript.

\section{Competing interests}

The authors declare that they have no competing interests.

Received: 24 January 2011 Accepted: 13 April 2011

Published: 13 April 2011

\section{References}

1. Chien CL: Magnetism and giant magneto-transport properties in granular solids. Annu Rev Mater Sci 1995, 25:129-160.

2. Anton I, Dabata ID, Vekas L: Application orientated researches on magnetic fluids. J Magn Magn Mater 1990, 85:219-226.

3. Gunther L: Quantum tunnelling of magnetization. Phys World 1990, 3:28-34.

4. McMickael RD, Shull RD, Swartzendruber L, Bennett LH, Watson RE: The magnetocaloric effect: role of magnetic anisotropy. J Magn Magn Mater 1992, 111:29-33.

5. Popplewell J, Sakhnini L: The dependence of the physical and magnetic properties of magnetic fluids on particle size. J Magn Magn Mater 1995, 149:72-78.

6. Raj K, Moskowitz R, Casciari R: Advances in ferrofluid technology. J Magn Magn Mater 1995, 149:174-180.

7. Haefeli U, Schuett W, Teller J, Zborowski M, Eds: Scientific and Clinical Applications of Magnetic Carriers. Plenum, New York; 1997.

8. Kryder MH: Ultrahigh-density recording technologies. MRS Bull 1996, 21:17-19.

9. Ammar S, Helfen A, Jouini N, Fievet F, Rosenman I, Villain F, Molinie P, Danot M: Magnetic properties of ultrafine cobalt ferrite particles synthesized by hydrolysis in a polyol medium. J Mater Chem 2001, 11:186-192.

10. Giri AK, Kirkpatrick EM, Moongkhamklang P, Majetich SA, Harris VG: Photomagnetism and structure in cobalt ferrite nanoparticles. Appl Phys Lett 2002, 80:2341-2343.

11. Giri AK, Pellerin K, Pongsaksawad W, Sorescu M, Majetich S: Effect of light on the magnetic properties of cobalt ferrite nanoparticles. IEEE Trans Magn 2000, 36:3029-3031.

12. Shi $\mathrm{Y}$, Ding J, $\mathrm{Yin} \mathrm{H}: \mathrm{CoFe}_{2} \mathrm{O}_{4}$ nanoparticles prepared by the mechanochemical method. J Alloys Compd 2000, 308:290-295.

13. Johnson DW, Ghate BB, Wang FY: Advances in Ceramics. American Ceramic Society, Columbus, OH; 1985:15:27.

14. Veena Gopalan E, Joy PA, Al-Omari IA, Sakthi Kumar D, Yoshida Y, Anantharaman MR: On the structural, magnetic and electrical properties of sol-gel derived nanosized cobalt ferrite. J Alloys Compd 2009, 485:711-717.

15. Wang Y, Xu G, Yang L, Ren Z, Wei X, Weng W, Du P, Shen G, Han G: Hydrothermal synthesis of single-crystal bismuth ferrite nanoflakes assisted by potassium nitrate. Ceram Int 2009, 35:1285-1287.

16. Priyadharsini P, Pradeep A, Chandrasekaran G: Novel combustion route of synthesis and characterization of nanocrystalline mixed ferrites of $\mathrm{Ni}-\mathrm{Zn}$. J Magn Magn Mater 2009, 321:1898-1903.

17. Wang J, Chong PF, Ng SC, Gan LM: Microemulsion processing of manganese zinc ferrites. Mater Lett 1997, 30:217-221.

18. Ravindranathan P, Patil KC: A low temperature path to ultrafine ferrites. Am Ceram Soc Bull 1987, 66:688-692.

19. Pillai V, Shah DO: Synthesis of high-coercivity cobalt ferrite particles using water-in-oil microemulsions. J Magn Magn Mater 1996, 163:243-248. 
20. Lal M, Sharma DK, Singh M: Effect of processing and polarizer on the electrical properties of Mn-Zn ferrities. Indian J Pure Appl Phys 2005, 43:291-294.

21. Gharagozlou M: Synthesis, characterization and influence of calcinations temperature on magnetic properties of nanocrystalline spinel Co-ferrite prepared by polymeric precursor method. J Alloys Compd 2009, 486:660-665.

22. Wu KH, Yu CH, Chang YC, Horng DN: Effect of $\mathrm{pH}$ on the formation and combustion process of sol-gel auto-combustion derived NiZn ferrite/ $\mathrm{SiO}_{2}$ composites. J Solid State Chem 2004, 177:4119-4125.

23. Zhou ZH, Xue JM, Chan HSO, Wang J: Nanocomposites of $\mathrm{ZnFe}_{2} \mathrm{O}_{4}$ in silica: synthesis, magnetic and optical properties. Mater Chem Phys 2002 75:181-185.

24. Paterson JH, Devine R, Phelps ADR: Complex permeability of soft magnetic ferrite/polyester resin composites at frequencies above $1 \mathrm{MHz}$. J Magn Magn Mater 1999, 196:394-396.

25. Arshak Kl, Ajina A, Egan D: Development of screen-printed polymer thick film planar transformer using $\mathrm{Mn}-\mathrm{Zn}$ ferrite as core material. Microelectron J 2001, 32:113-116.

26. Grigorieva NA, Grigoriev SV, Okorokov Al, Eckerlebe H, Elisrrv AA, Lukashin AV, Napolskii KS: Iron nanowires embedded in mesoporous silica: Polarized neutron scattering study. Physica E 2005, 28:286-295.

27. Prokes $S M$, Carlos WE, Lenward S, Stephen L, James G: Formation of ferromagnetic Ni/SiO 2 nanospheres. Mater Lett 2002, 54:85-88.

28. Manova E, Tsoncheva T, Paneva D, Rehspringer JL, Tenchev K, Mitov I, Petrov L: Synthesis, characterization and catalytic properties of nanodimensional nickel ferrite/silica composites. Appl Catal A 2007, 317:34-42

29. Guang-She L, Li-Ping L, SmithJr RL, Inomata H: Characterization of the dispersion process for $\mathrm{NiFe}_{2} \mathrm{O}_{4}$ nanocrystals in a silica matrix with infrared spectroscopy and electron paramagnetic resonance. J Mol Struct 2001, 560:87-93.

30. Wu KH, Huang WC, Yang CC, Hsu JS: Sol-gel auto-combustion synthesis of $\mathrm{Ni}_{0.5} \mathrm{Zn}_{0.5} \mathrm{Fe}_{2} \mathrm{O}_{4} /\left(\mathrm{SiO}_{2}\right)_{\mathrm{x}}(\mathrm{x}=10,20,30$ wt.\%) nanocomposites and their characterizations. Mater Res Bull 2005, 40:239-248.

31. Brinker CJ, Scherer GW: Sol-gel science. The Physics and Chemistry of SolGel Processing, Academic Press, Boston; 1990.

32. Pierre AC: Introduction to Sol-Gel Processing. Kluwer Academic Publishers, Boston; 1998.

33. Gill I, Ballesteros A: Encapsulation of biologicals within silicate, siloxane, and hybrid sol-gel polymers: an efficient and generic approach. J Am Chem Soc 1998, 120:8587-8598.

34. Meyer M, Fischer A, Hoffmann H: Novel ringing silica gels that do not shrink. J Phys Chem B 2002, 106:1528-1533.

35. Huang $X$, Chen Z: A study of nanocrystalline $\mathrm{NiFe}_{2} \mathrm{O}_{4}$ in a silica matrix. Mater Res Bull 2005, 40:105-113.

36. Sui YP, Huang XF, Ma ZY, Li W, Qiao F, Chen $K$, Chen KJ: The effect of thermal annealing on crystallization in a-Si:H/SiO ${ }_{2}$ multilayers by using layer by layer plasma oxidation. J Phys: Condens Matter 2003, 15:5793-5800

37. Xiao $S H, X u H J, H u J, L i ~ L Y, L i X J$ : Dependence of structural and magnetic properties of $\mathrm{CoFe}_{2} \mathrm{O}_{4} / \mathrm{SiO}_{2}$ nanocomposites on annealing temperature and component ratio. Physica E 2008, 40:3064-3067.

38. Cullity BD: Elements of X-Ray Diffraction. Addison-Wesley Publishing Company, Reading Massachusetts; 1956, 259.

39. Izutsu H, Nair PK, Maeda K, Kiyozumi Y, Mizukami F: Structure and properties of $\mathrm{TiO}_{2}-\mathrm{SiO}_{2}$ prepared by sol-gel method in the presence of tartaric acid. Mater Res Bull 1997, 32:1303-1311.

40. Huang $\mathrm{XH}$, Chen $\mathrm{ZH}$ : Sol-gel preparation and characterization of $\mathrm{CoFe}_{2} \mathrm{O}_{4}-\mathrm{SiO}_{2}$ nanocomposites. Solid State Commun 2004, 132:845-850.

41. Caizer C, Stefanescu M: Magnetic characterization of nanocrystalline NiZn ferrite powder prepared by the glyoxylate precursor method. J Phys D: Appl Phys 2002, 35:3035-3040.

42. Huang $\mathrm{XH}$, Chen $\mathrm{ZH}: \mathrm{CoFe}_{2} \mathrm{O}_{4}$ nanoparticles hosted in silica xerogels. Scr Mater 2006, 54:169-173.

43. Mohallem NDS, Seara LM: Magnetic nanocomposite thim films of $\mathrm{NiFe}_{2} \mathrm{O}_{4} / \mathrm{SiO}_{2}$ prepared by sol-gel process. Appl Surf Sci 2003, 214:143-150.

44. Shafi KVPM, Gedanken A, Prozorov R, Balogh J: Sonochemical preparation and size-dependent properties of nanostructured $\mathrm{CoFe}_{2} \mathrm{O}_{4}$ particles. Chem Mater 1998, 10:3445-3450.
45. Rajendran M, Pullar RC, Bhattacharya AK, Das D, Chintalapudi SN, Majumdar CK: Magnetic properties of nanocrystalline $\mathrm{CoFe}_{2} \mathrm{O}_{4}$ powders prepared at room temperature: variation with crystallite size. J Magn Magn Mater 2001, 232:71-83.

46. Coey JMD: Noncollinear spin arrangement in ultrafine ferrimagnetic crystallites. Phys Rev Lett 1971, 27:1140-1142.

doi:10.1186/1752-153X-5-19

Cite this article as: Gharagozlou: Influence of calcination temperature on structural and magnetic properties of nanocomposites formed by Co-ferrite dispersed in sol-gel silica matrix using tetrakis(2-hydroxyethyl) orthosilicate as precursor. Chemistry Central Journal 2011 5:19.

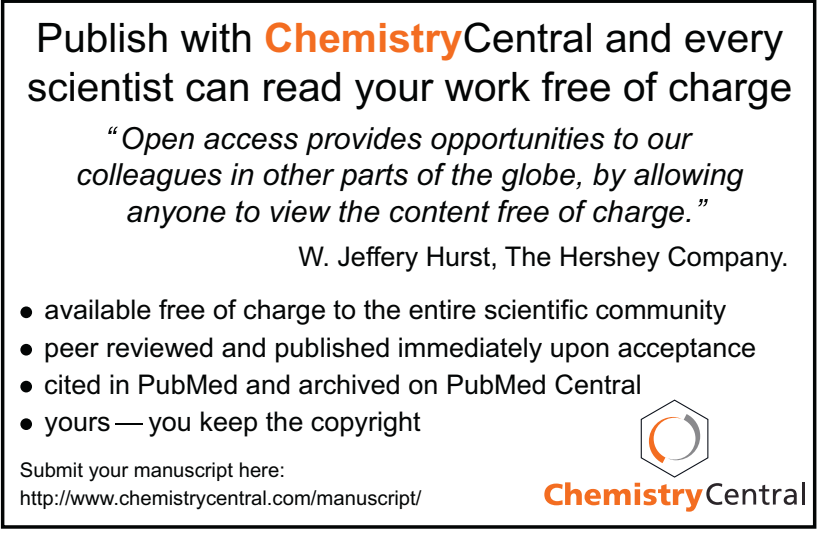

